\title{
A REVIEW ON APPLICATIONS OF CARBON NANOTUBES IN AUTOMOBILES
}

\author{
Akshay Krishnan, Sarthak Shandilya, Balasubramanya H S and Pushparaj Gupta \\ Department of Mechanical Engineering, Ramaiah Institute of Technology, \\ MSR Nagar, Bengaluru, India
}

\begin{abstract}
The Automotive industry continues to be a budding and growing industry wherein new and innovative ideas and technologies find very promising applications periodically. This review paper to a great extent will look into the relevance of carbon nanotubes as a way to improve the performance of "on the road" automobiles in the field of fuel component systems particularly to get a better fuel efficiency. Further the implementation of Carbon Nanotubes shall be dealt in depth with a focus on automobile application. Furthermore, CNTs have been found to have exceptional morphological properties and therefore are promising as reinforcement material in the composite structures along with polymers for many automotive applications. This could also become the basis for weight reduction. Needless to say, CNTs can be utilised for the production of geometrical, irregular or complex shapes and designs with fairly inexpensive and relatively abundant raw materials vis a vis the current conventional processes of fabrication. Therefore cost effectiveness and productivity could also be achieved in scale and scope.
\end{abstract}

Keywords: Carbon Nanotubes, Automobile, Fuel Efficiency, Nanotechnology.

Cite this Article: Akshay Krishnan, Sarthak Shandilya, Balasubramanya H S and Pushparaj Gupta, A Review on Applications of Carbon Nanotubes in Automobiles. International Journal of Mechanical Engineering and Technology 11(1), 2020, pp. 204-210.

https://iaeme.com/Home/issue/IJMET?Volume=11\&Issue=1

\section{INTRODUCTION}

Carbon nanotubes or CNTs basically consist of rolled up sheets of single layered carbon atoms (graphene). Further Carbon nanotubes can be categorised as [1,14]: Single Wall Carbon Nanotubes (SWCNT) [Fig(1)], Double Wall Carbon Nanotubes (DWCNT) [Fig(2)] \& Multi Wall Carbon Nan- otubes (MWCNT) [Fig(3)]. SWCNT can reach diameter less than 1 nanometer. DWCNT has one nanotube nested within another. The nanotube inside has a smaller diameter. The spatial gap between the two diameters results in the varying interactions between the nanotubes. This means that the outer nanotube can be modified without any modifications in the inner nanotube and therefore this results in interesting characteristics. MWCNT consists of several concentrically interlinked nanotubes which can reach diameters more than 100 nanometers. 
Historically, progress of automotive industry is replete with outstanding examples of new materials and usage of their properties to bring about disruption in the trend. Therefore, to have better cars in the future our industry needs to change and it needs to change for the better. The rapid progress of CNTs shows great promise for the betterment of this industry. The main reasons for using CNTs is due to its extraordinary properties are High flexibility without any significant damage, Low Thermal Expansion Coefficient, Very High Tensile Strength. Each of the above mentioned properties in its own respect can merit a lot of usage and in combination can be used to improve the efficiency and structural characteristics of the car.

\section{SYNTHESIS OF CARBON NANOTUBES}

The most popular mode of producing high volume CNTs is by using Chemical Vapour Deposition (CVD) which generally uses fluidised bed reactors as from Fig.(1) that allows uniform gas diffusion and heat transfer to metal catalyst nanoparticles. Scaling up the production can be done with the help of low cost feed stocks $[1,6,15]$

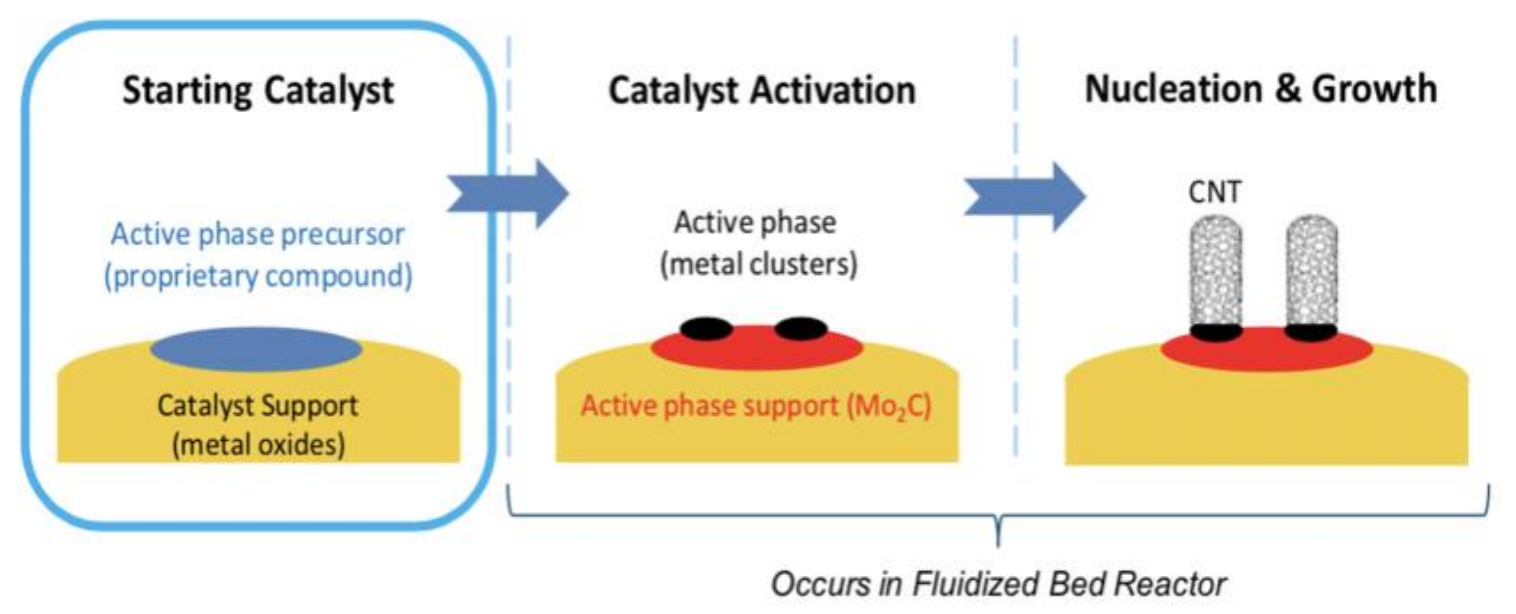

Figure 1 Chemical vapor deposition

Whereas to produce small sample sizes, solution blending proves to be a very effective production technique [Fig(2)]. It is a three step process involving dispersion of nanotubes in suitable solvent, mixing with polymer and then recovering the composite by casting a film. [2]

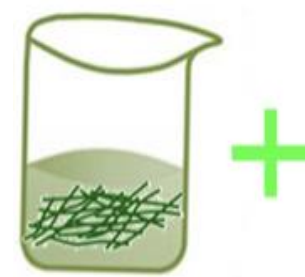

Polymer

solution

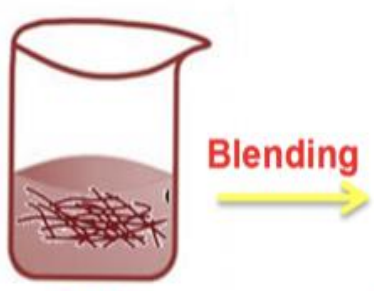

CNTs dispersion

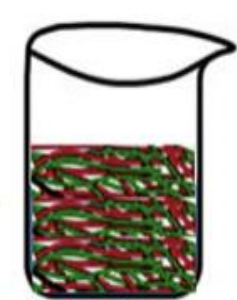

CNTs/Polymer mixture

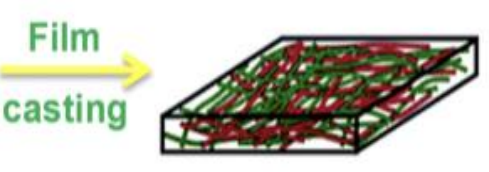

Nanocomposite film

Figure 2 Solution blending 


\section{NITROGEN DOPED CNT EFFECT ON FUEL CONSUMPTION}

The current industry application of fuel cells has been to use the more expensive platinumbased electrocatalysts for oxygen reduction reaction (ORRs). One of the basic tenets of manufacturing is mass production resulting in a more cost effective product. Current fuel cells are no exception to this rule. However CNTs have the potential to further make manufacturing process cost efficient through increased productivity. Experiments have been conducted through introduction of dopants to validate the above claims. [3,5]

Nitrogen doped Carbon Nanotubes (VA-NCNTs), which are Vertically Aligned, can act as a metal-free electrode with a much better electrocatalytic activity and a stabilising the process over a period of time. Synthesis of this fuel cell can be achieved by a similar way with the help of Chemical Vapour Deposition (CVDs) or high-temperature and high- pressure reactions.[4]

Alternatively pyrolyzing melamine under $\mathrm{Ar}$ at elevated temperatures of $800-980{ }^{\circ} \mathrm{C}$ using the CVD method can also be used to produce NCNTs. However this method does not produce the desired configuration of the NCNTs. It will pro- duce a bamboo like structure which affects the configuration of nitrogen when introduced and hence producing properties not meeting the required standards. [4]

Nitrogen Doping has a very important role in lithium ion batteries because NCNTs are much more reactive to metal oxide nanoparticle deposition which in turn further enhance the storage capacity. Therefore by having many favourable $\mathrm{N}$ - doped sites the storage capacity of the battery also increases. The above data shows experiments conducted on VA- NCNTs vs Conventional cells a poison methanol was introduced to the fuel cells, methanol and Carbon monoxide. [4]

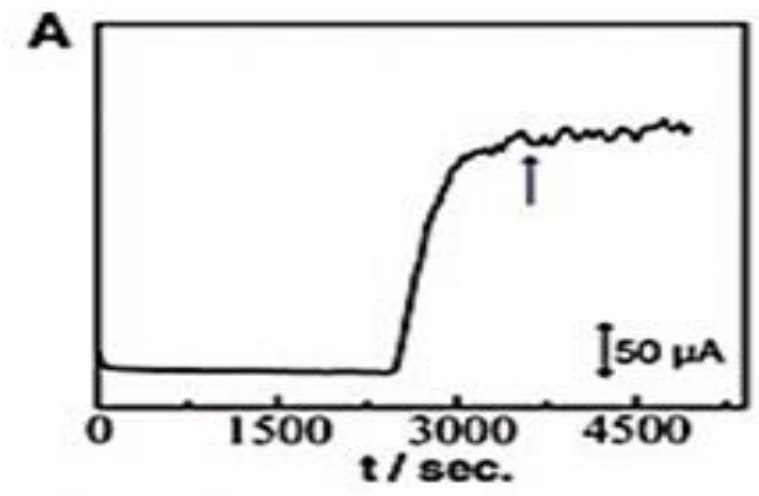

Figure 3 A: I-t Chronoamperometric values procured at the VA- NCNT/GC electrode when introduced to Methanol.

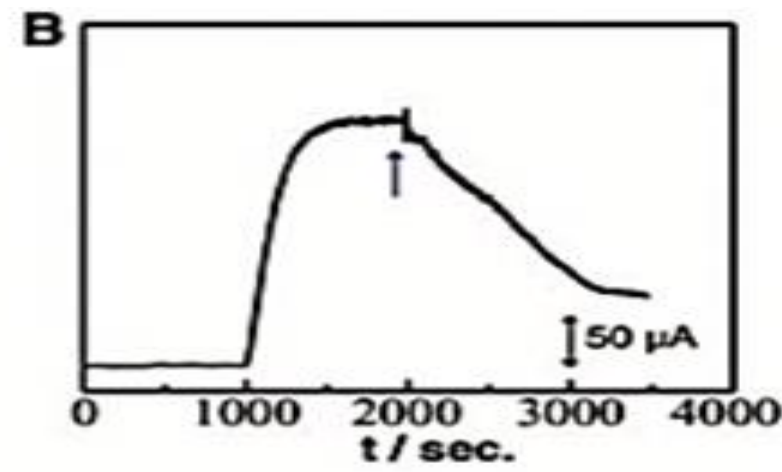

Figure 3B: I-t Chronoamperometric values procured at the Pt- C/GC electrode when introduced to Methanol. 


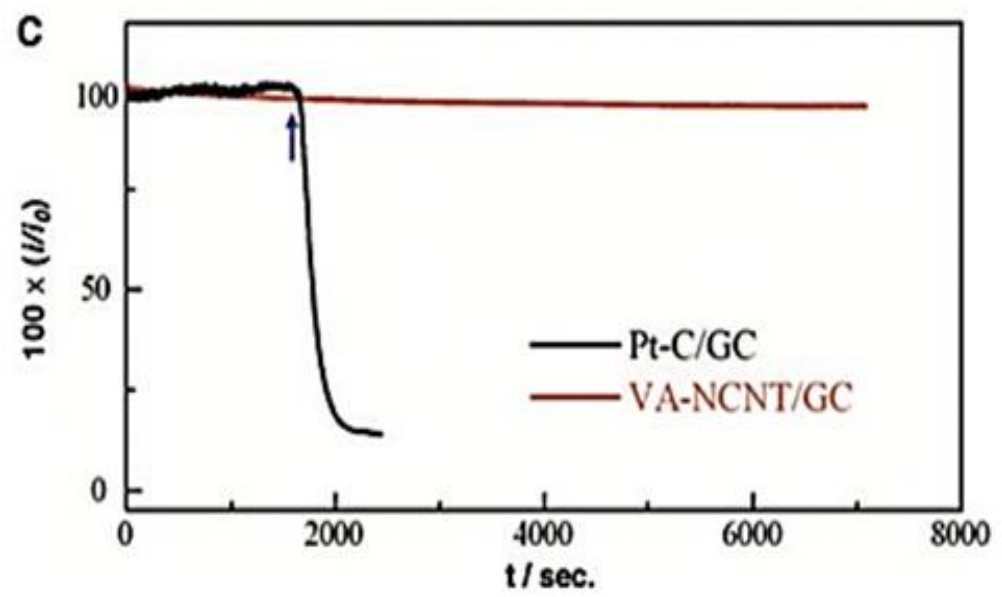

Figure 3C: I-t Chronoamperometric values for the Pt-C/GC and VA-NCNT/GC electrodes when introduced to $\mathrm{CO}$.

Figure 3 (A), (B) and (C) shows I-t characteristics for different electrode materials introducing into meehanol. The graphs demonstrate that VA-NCNT as better stability characteristics compared to Pt-

C/GC.

\section{CNT COATINGS}

CNT Coating is turning out to be one of the best coatings finding its usage in numerous ways. It not only has high anticorrosive properties but also provides additional strength and stiffness while still having cathodic protection. As time is running out so is our resources and the scarcity of Indium is making the production of Indium Tin oxide (ITO) much more expensive. The usage of CNT coating because it is more flexible, transparent and, less brittle as compared to ITO, will soon come out of R\&D laboratories to the production processes in the automobile industry, thus transforming from and idea to a reality. [6]

These appealing properties of CNTs can be implemented to the automobile industry to create a long lasting chassis and body which will not corrode under extreme conditions. CNT Coating is turning out to be one of the best coatings finding its usage in numerous ways. It not only has high anticorrosive properties but also provides additional strength and stiffness while still having cathodic protection. As time is running out so is our resources and the scarcity of Indium is making the production of Indium Tin oxide (ITO) much more expensive. The usage of CNT coating because it is more flexible, transparent and, less brittle as compared to ITO, will soon come out of $\mathrm{R} \& \mathrm{D}$ laboratories to the production processes in the automobile industry, thus transforming from and idea to a reality [Fig. (4)] [6]. These appealing properties of CNTs can be implemented to the automobile industry to create a long lasting chassis and body which will not corrode under extreme conditions.

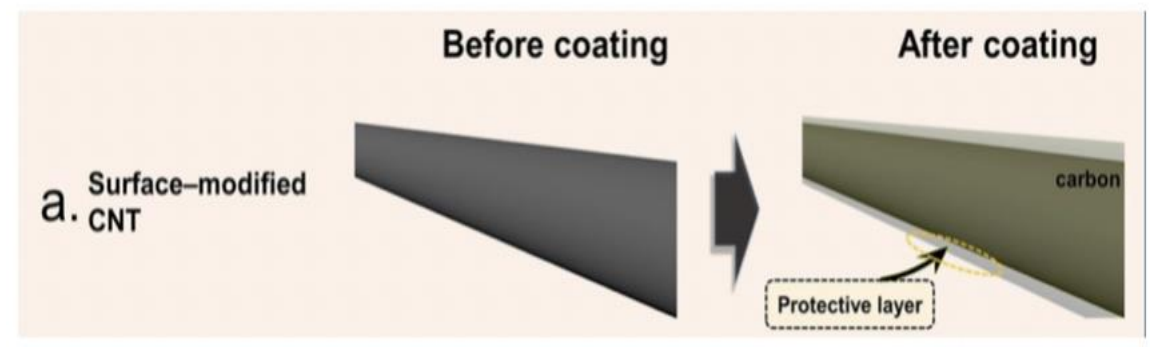

Figure 4 Surface coating on CNT 


\section{MECHANICAL PROPERTIES OF CNTS}

Mechanical properties of materials play a pivotal role in improving the form and function of an automobile. Historically the automobile companies use alloy steel for its body and have been no doubt very successful but the industry is still looking towards how to tackle with corrosive properties of steel. The alternative to steel, because of its heaviness, is to use aluminium but this replacement can happen making it expensive. Here comes the usage of CNTs, because of its strength, hardness and bending properties, better than both steel and aluminium and also cheaper than two metals.

\section{STRENGTH OF CNTS: [7,9,10]}

As per industry standard Young's modulus is used as a measure of strength and CNT is found to be stronger than steel and aluminium. Further, the cylindrical graphitic structure makes the entire body seamless and defect-free. Environmental factors such a temperature changes, pressure, moisture, etc, while selecting the material, conducting experiments and doing comparative analysis of CNT with respect alloy steel and aluminium. These factors have a considerable bearing and directly affect the structural integrity of the material.

Further, one needs to take into consideration whether the material is brittle and ductile. While conducting experiments, fracture stress becomes the criterion for brittle and yield stress becomes the criterion for ductile materials. At a micro level the strength and the breaking mechanisms of any material depend on the movement of the dislocations present within.

\section{CNTS HARDNESS:[11,12,13]}

Single Walled Carbon Nanotube, do not show any plastic deformation up to 25GPA. Further, conventional experiments on super hard phase nanotubes have shown to withstand 55GPA and with a bulk modulus of 462GPA. This is where the technology has advanced to such an extent that super hard phase nanotubes surpass even the hardness properties of diamond. The introduction of Polypropylene in CNTs (PP-CNT) show remarkable increase in hardness. It is depicted from Fig. 8 [13]

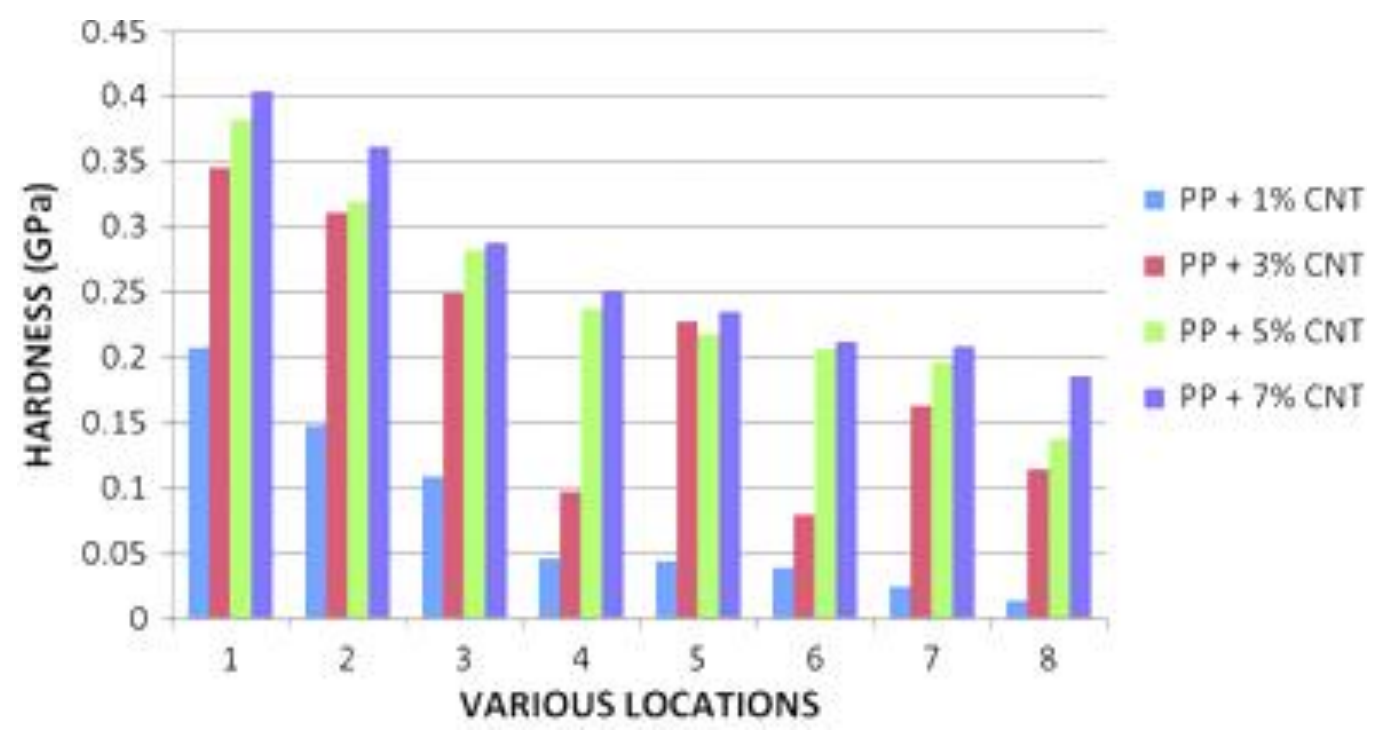

Figure 8 Effect of CNT hardness of PP 


\section{CNTS BENDING PROPERTIES: [8]}

Both SWCNT's \& MWCNT's show large bending constants. Generally it is observed that MWCNT is straight. However we may have to introduce faults in specific locations in the structure to create a bend. A point to note is that introduction of faults results in a high elastic constant in those locations where a sharp bend is required. It is obvious that such properties facilitate manufacturing of geometric or irregular or intricate shapes of CNTs to produce various elements of an automobile.

\section{CONCLUSION}

Historically, new inventions have facilitated to replace the old making way to a better product, application and its utility wherein CNTs seem to be very promising to bring about a breakthrough in the automotive sector. The review paper has highlighted the exceptional properties of CNTs which in turn can replace steel or aluminium which are becoming a scarce natural resource and plastics with its own environmental hazards due to non biodegradability. The caveat to all this is that purification process of CNTs has to improve in order to increase its viability. Judging by the rapid progress in technology happening by leaps and bounds, the day is not far off when CNT will find its rightful place in the automobile industry.

\section{REFERENCES}

[1] Dr S Madhu, "Applications of carbon nano tubes (CNT) in automobiles," International Journal of Applied Engineering Research, 2015.

[2] Moniruzzaman, Mohammad \& Winey, Karen. (2006). Polymer Nanocomposites Containing Carbon Nanotubes. Macromolecules. 39.

[3] R. Czerw, M. Terrones, J.-C. Charlier, X. Blase, B. Foley, R. Kamalakaran, N. Grobert, H. Terrones, P. M. Ajayan, W. Blau, D. Tekleab, M. Ru hle, and D. L. Carroll, "Identification of Electron Donor States in N-doped Carbon Nanotubes", American Chemical Society, 2001

[4] Kuanping Gong, "Nitrogen-Doped Carbon Nanotube Arrays with High Electrocatalytic Activity for Oxygen Reduction", Science 323, 2009.

[5] Zhu Chen, Drew Higgins, Zhongwei Chen, "Nitrogen doped carbon nanotubes and their impact on the oxygen reduction reaction in fuel cells", Composites Science and Technology, 2010.

[6] Michael F. L. De Volder, Sameh H. Tawfick, Ray H. Baughman, A. John Hart, "Carbon Nanotubes: Present and Future Commercial Applications”, Science, 2013.

[7] J.-P. Salvetat, J.-M. Bonard, N.H. Thomson, A.J. Kulik, L. Forro, W. Benoit, L. Zuppiroli, "Mechanical properties of carbon nanotubes", Springer-Verlag, 1999.

[8] Rodney S Ruoff, Donald C Lorents, "Mechanical and Thermal Properties of Carbon Nanotubes", Pergamon, 1995.

[9] Li, Fang \& Cheng, Hui-Ming \& Bai, S \& Su, Gizem \& S. Dresselhaus, M. (2000). Tensile strength of single-walled carbon nanotubes directly measured from their macroscopic ropes. Applied Physics Letters. 77.

[10] R.J. Sager, P.J. Klein, D.C. Lagoudas, Q. Zhang, J. Liu, L. Dai, J.W. Baur, "Effect of carbon nanotubes on the interfacial shear strength of T650 carbon fiber in an epoxy matrix", Composites Science and Technology, 2008.

[11] Uddin, S.M., Mahmud, T., Wolf, C., Glanz, C., Kolaric, I., Volkmer, C., Höller, H., Wienecke, U., Roth, S., Fecht, H-J., Effect of size and shape of metal particles to improve 
Akshay Krishnan, Sarthak Shandilya, Balasubramanya H S and Pushparaj Gupta

hardness and electrical properties of carbon nanotube reinforced copper and copper alloy composites, Composites Science and Technology (2010)

[12] M. Popov, M. Kyotani, R. J. Nemanich, and Y. Koga, "Superhard phase composed of single-wall carbon nanotubes”, American Physical Society, 2002.

[13] Ashok Gandhi R., Jayaseelan V., Palani Kumar K., Raghunath B.K., Krishnaraj S. (2019) Effect of Carbon Nano Tubes (CNT) on Hardness of Polypropylene Matrix. In: Lakshminarayanan A., Idapalapati S., Vasudevan M. (eds) Advances in Materials and Metallurgy. Lecture Notes in Mechanical Engineering. Springer, Singapore.

[14] Mohsen Mohseni, Bahram Ramezanzadeh, Hossein Yari and Mohsen Moazzami Gudarzi, "The Role of Nanotechnology in Automotive Industries", Chapter 1, Iran, 2012.

[15] Anvar Zakhidov, "Carbon Nanotubes-The Route Toward Applications," Science Journal, 2002. 